\title{
Melatonin Transmits Photoperiodic Signals through the MT1 Melatonin Receptor
}

\author{
Shinobu Yasuo, ${ }^{1}$ Takashi Yoshimura, ${ }^{2,3}$ Shizufumi Ebihara, ${ }^{4}$ and Horst-Werner Korf ${ }^{1}$ \\ ${ }^{1}$ Dr. Senckenbergische Anatomie, Institute of Anatomie II, Goethe University Frankfurt, 60590 Frankfurt am Main, Germany, ${ }^{2}$ Laboratory of Animal \\ Physiology, ${ }^{3}$ Avian Bioscience Research Center, and ${ }^{4}$ Division of Biomodeling, Graduate School of Bioagricultural Sciences, Nagoya University, Nagoya \\ 464-8601, Japan
}

\begin{abstract}
Melatonin transmits photoperiodic signals that regulate reproduction. Two melatonin receptors (MT1 and MT2) have been cloned in mammals and additional melatonin binding sites suggested, but the receptor that mediates the effects of melatonin on the photoperiodic gonadal response has not yet been identified. We therefore investigated in mice whether and how targeted disruption of MT1, MT2, or both receptor types affects the expression level of two key genes for the photoperiodic gonadal regulation, type 2 and 3 deiodinase (Dio 2 and Dio3, respectively). These are expressed in the ependymal cell layer lining the infundibular recess of the third ventricle and regulated by thyrotropin produced in the pars tuberalis. In wild-type $\mathrm{C} 3 \mathrm{H}$ mice, Dio2 expression was constantly low, and no photoperiodic changes were observed, whereas Dio3 expression was upregulated under short-day conditions. In C3H with targeted disruption of MT1 and MT1/MT2, Dio2 expression was constitutively upregulated, Dio3 expression was constitutively downregulated, and the photoperiodic effect on Dio3 expression was abolished. Under short-day conditions, C3H with targeted disruption of MT2 displayed similar expression levels of Dio2 and Dio3 as wild-type animals, but they responded to long-day condition with a stronger suppression of Dio3 than wild-type mice. Melatonin injections into wild-type C57BL mice suppressed Dio2 expression and induced Dio3 expression under long-day conditions. These effects were abolished in C57BL mice with targeted disruption of MT1. All data suggest that the melatonin signal that transmits photoperiodic information to the hypothalamo- hypophysial axis acts on the MT1 receptor.
\end{abstract}

\section{Introduction}

In many mammalian species living in temperate zones, changes in photoperiod regulate various functions including reproduction. Transmission of photoperiodic information involves melatonin secreted from the pineal gland during darkness. The duration of the melatonin signal encodes the length of the night (Bartness et al., 1993). Two melatonin receptor subtypes, MT1 and MT2, are identified in mammals (for review, see von Gall et al., 2002b). MT1 plays an important role in rodent brain, and pituitary and $\left[{ }^{125} \mathrm{I}\right]$ iodomelatonin binding disappears in MT1deficient mice (Liu et al., 1997). MT2 is also expressed in the brain including the suprachiasmatic nucleus, where it mediates the phase shifting responses to melatonin (Liu et al., 1997; Dubocovich et al., 1998). Moreover, melatonin may act on other binding sites (MT3) (Boutin et al., 2005). The receptor type that mediates the action of melatonin as photoperiodic signal remains unclear. In Djungarian hamsters, which show a strong photoperiodic re-

Received Jan. 12, 2009; revised Jan. 28, 2009; accepted Feb. 3, 2009.

This work was supported by the Alfons und Gertrud Kassel-Stiftung, Frankfurt am Main, Germany. We thank David R. Weaver for providing the mice with targeted deletion/disruption of the MT1 and MT2 receptors and Claudia Unfried for technical help. S.Y. is sponsored by Japan Society for the Promotion of Science Postdoctoral Fellowship for Research Abroad.

This article is freely available online through the J Neurosci Open Choice option.

Correspondence should be addressed to Dr. Horst-Werner Korf, Dr. Senckenbergische Anatomie, Institute of Anatomy II, Goethe University Frankfurt, Theodor-Stern-kai 7, 60590 Frankfurt am Main, Germany. E-mail: korf@em.uni-frankfurt.de.

DOI:10.1523/JNEUROSCI.0145-09.2009

Copyright @ 2009 Society for Neuroscience $\quad$ 0270-6474/09/292885-05\$15.00/0 sponse of gonads, the MT2 receptor gene cannot encode a functional receptor because of two nonsense mutations within the coding region (Weaver et al., 1996), suggesting that MT2 is not necessary for the photoperiodic response in this species. However, direct evidence for distinct functions of MT1 and MT2 receptor types in photoperiodic regulation is missing.

Experiments with Japanese quail have provided novel data about the molecular mechanisms of photoperiodic gonadal regulation. Long-day stimulus induces the expression of thyrotropin (TSH) $\beta$ subunit (TSHB) in the hypophysial pars tuberalis (PT), and TSH induces Dio2 expression in the ependymal cell layer (EC) lining the infundibular recess of the third ventricle via TSH receptors (Nakao et al., 2008). DIO2 converts thyroxine into bioactive triiodothyronine, which stimulates the gonadal axis (Yoshimura et al., 2003). Notably, the expression of Dio3, which encodes for thyroid hormone-inactivating enzyme, is suppressed by long-day stimulus. Thus, the changing ratio between expression of Dio2 and Dio3 would serve as "gene switch" for photoperiodic gonadal regulation (Yasuo et al., 2005). This molecular machinery is conserved in mammals. The expression of Dio2 and Dio3 is regulated by the photoperiod and melatonin in Syrian and Djungarian hamsters (Watanabe et al., 2004; Revel et al., 2006; Watanabe et al., 2007b; Yasuo et al., 2007), and TSHB is involved in the photoperiodic regulation of Dio2 in sheep (Hanon et al., 2008). Most interestingly, the expression of Dio2, Dio3, and TSHB is also under photoperiodic control in mice whose gonadal size is not affected by the photoperiod (Ono et al., 2008). This study has established that mice are suitable models to investigate 
molecular mechanisms of photoperiodic regulation at the hypothalamo-hypophysial level and has opened the way to use genetically manipulated mice to further analyze the molecular mechanisms underlying photoperiodic regulation. Here, we examined the effects of targeted disruption of melatonin receptors (MT1, MT2, and both subtypes) on the expression of Dio2 and Dio3 under various photoperiodic conditions in mice to identify the receptor type through which melatonin exerts its action as a photoperiodic messenger.

\section{Materials and Methods}

Animals. All animal experiments reported here were conducted under a protocol in accordance with the Policy on the Use of Animals in Neuroscience Research, and the Policy on Ethics, as approved by the Society for Neuroscience, and were consistent with Federal guidelines of Germany and the European Communities Council Directive. Mice with targeted disruption of MT1, MT2, or both subtypes $\left(M T 1^{-1-}, M T 2^{-1-}\right.$, and $\left.M T 1^{-1-} M T 2^{-1-}\right)$ on a melatonin-proficient $\mathrm{C} 3 \mathrm{H} / \mathrm{HeN}$ genetic background have been described previously (von Gall et al., 2002a, 2005; Jilg et al., 2005). Genotypes were determined by PCR amplification of genomic DNA extracted from the tail as described previously (Liu et al., 1997; Jin et al., 2003). Male mice (4-5 weeks old) of each genotype were housed under short-day condition [ $8 \mathrm{~h}$ of light, $16 \mathrm{~h}$ of darkness (8L:16D)] for at least 3 weeks. When mice were 7-8 weeks old, they were separated into two groups: one group was transferred to and kept under long-day condition (16L:8D) for 2 weeks; the other group remained under short-day condition (8L:16D) for an additional 2 weeks. For the investigation of the temporal expression of Dio2 and Dio3 in wild-type C3H mice, the animals were killed at Zeitgeber time (ZT: ZT0 corresponds to the light onset) $2,8,14,20(n=$ $3-4 /$ time point/lighting condition) by decapitation. To investigate the effects of targeted disruption of melatonin receptors on Dio2 and Dio 3 expression, transgenic $\mathrm{C} 3 \mathrm{H}$ mice were killed in the middle of the light phase (ZT4 for 8L:16D, ZT8 for 16L:8D, $n=5-6 /$ lighting condition). These time points were selected because the expression of Dio2, Dio3, and TSHB showed significant differences in CBA/N mice at this time (Ono et al., 2008). Animal facilities were maintained at a temperature of $22 \pm$ $1{ }^{\circ} \mathrm{C}$. Standard diet pellet for rodents and water were available ad libitum and were replenished at least twice a week.

Melatonin injections. In our preliminary experiments, Dio2 and Dio3 expression of wild-type $\mathrm{C} 3 \mathrm{H}$ mice did not respond to melatonin injections given at ZT14 for 3 weeks (data not shown), whereas Dio2 and Dio3 expression was clearly affected by melatonin injections in wild-type C57BL mice (Ono et al., 2008). Therefore, mice with targeted disruption of MT1 on C57BL genetic background (Liu et al., 1997) were used for the melatonin injection experiments. Male mice (4-5 weeks old) of wildtype and $M T 1^{-1-}$ genotype were housed under long-day condition (16L: $8 \mathrm{D})$ for at least 1 week before the experiments. Thereafter, either melatonin $(6 \mu \mathrm{g}$ melatonin dissolved in $0.1 \mathrm{ml} 5 \%$ ethanol and $0.9 \% \mathrm{NaCl})$ or vehicle $(0.1 \mathrm{ml} 5 \%$ ethanol and $0.9 \% \mathrm{NaCl})$ were subcutaneously injected at ZT14 for 1 week. This period was chosen because our preliminary experiments showed that 1 week of injections was sufficient to suppress Dio2 and to induce Dio3 expression in wild-type C57BL mice.

In situ hybridization. In situ hybridization was performed according to Yoshimura et al. (2000). Antisense and sense 45-mer oligonucleotide probes for mouse Dio2 (sense: $5^{\prime}$-ctgcctcttcctggcgctctatgactcggtcattctgctcaagca- $3^{\prime}$ ) and mouse Dio3 (sense: $5^{\prime}$-ggcaccatcatgtaccagggaggccgtggccccgacggttaccag- $3^{\prime}$ ) were labeled with $\left[{ }^{33} \mathrm{P}\right] \mathrm{dATP}$ (NEN Life Science
Products) using terminal deoxynucleotidyl transferase (Invitrogen). Coronal frozen sections ( $20 \mu \mathrm{m}$ thick) of the mediobasal hypothalamus were prepared using a cryostat. Hybridization was performed overnight at $42^{\circ} \mathrm{C}$. After washing, sections were air dried and apposed to Biomax-MR film (Kodak) for 3 weeks. In each experiment, ${ }^{14} \mathrm{C}$ microscales (GE Healthcare Bio-Sciences) were included in the cassette; the relative optical density was measured by use of National Institutes of Health Image software and converted into the radioactivity value ( $\mathrm{nCi}$ ) using the ${ }^{14} \mathrm{C}$ standard measurements. Data were normalized by subtracting the value determined in the lateral hypothalamic area, which is located in the same section and does not exhibit a hybridization signal (Watanabe et al., 2004).

\section{Results}

Temporal expression of Dio2 and Dio3 in wild-type C3H mice To examine whether $\mathrm{C} 3 \mathrm{H}$ mice in our breeding colony respond to long or short photoperiods with changes in the expression of key photoperiodic genes, we investigated the expression of Dio2 and Dio3 in the EC of wild-type $\mathrm{C} 3 \mathrm{H}$ mice kept under long- and short-day conditions at four different Zeitgeber time points. Dio2 was expressed at low levels throughout a 24 -h cycle, and its expression showed no diurnal variation in mice kept under long- or short-day conditions (one-way ANOVA, $p>0.05$ ) (Fig. 1). Twoway ANOVA did not reveal a significant difference in relation to the photoperiodic condition ( $p>0.05$ ) (Fig. 1). Dio3 expression tended to show diurnal variation with high levels during the first half of the day (one-way ANOVA, $p=0.0791$ for long days; $p=$ 0.1403 for short days) (Fig. 1). The expression of Dio3 differed significantly between mice kept under long- and short-day conditions (two-way ANOVA, $p<0.01$ ) (Fig. 1). When each time point was compared, significant differences were found at ZT2 and 8 ( $t$ test, $p<0.05$ ). Sense probes for Dio2 and Dio3 did not detect any signal in the EC (data not shown). 

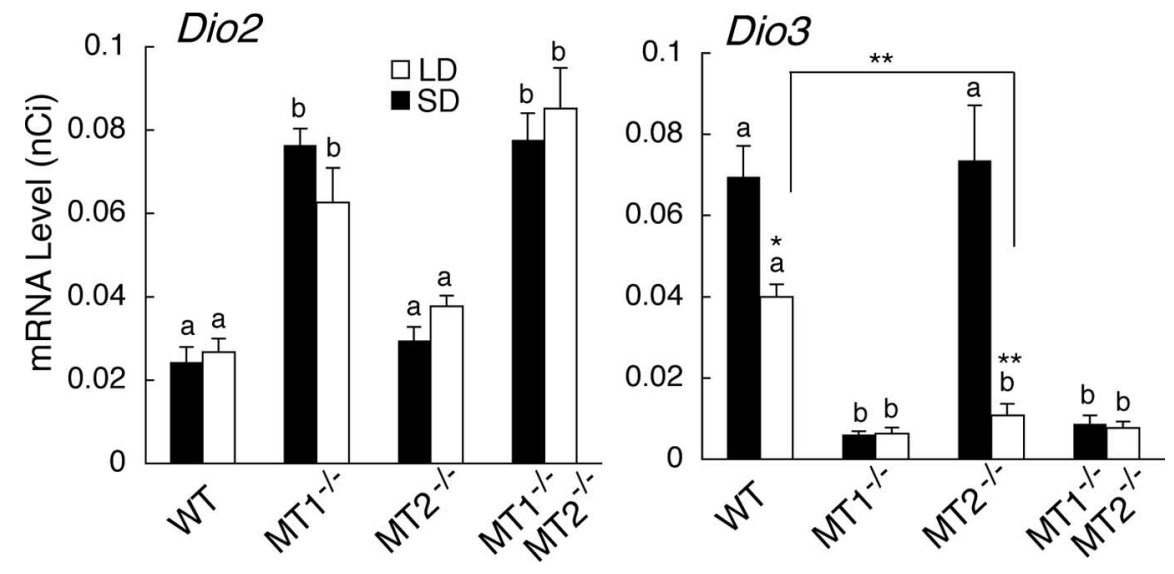

Figure 2. Effects of targeted disruption of melatonin receptor types on the expression of Dio2 and Dio3 in the ependymal cell layer lining the infundibular recess of the third ventricle. $\mathrm{C} 3 \mathrm{H}$ wild-type (WT) and $\mathrm{C} 3 \mathrm{H}$ mice with targeted disruption of MT1 $\left(\mathrm{MT}^{-1-}\right)$, MT2 (MT2 $\left.{ }^{-1-}\right)$, and both receptor types (MT1 ${ }^{-1-} \mathrm{MT} 2^{-1-}$ ) were kept either under short-day (SD, black bars) or under long-day (LD, white bars) conditions for 2 weeks. Different characters $(a, b)$ indicate the significance in each lighting condition (one-way ANOVA followed by Fisher's least significant difference post hoc test, $p<0.05 ; n=5-6$ ). Asterisks indicate significant differences between mice kept under SD and LD in each genotype or between mice of different genotypes ( $t$ test, ${ }^{*} p<$ $\left.0.05,{ }^{* *} p<0.01 ; n=5-6\right)$. Error bars indicate SEM.

\section{Effects of targeted disruption of melatonin receptors on Dio2 and Dio3 expression}

We examined photoperiodic changes in Dio2 and Dio3 expression in mice with targeted disruption of melatonin receptors $\left(M T 1^{-1-}, M T 2^{-1-}\right.$, and $\left.M T 1^{-1-} M T 2^{-1-}\right)$ at one time point in each lighting condition [middle of the light phase: ZT4 for short days (8L:16D), ZT8 for long days (16L:8D)]. These time points were selected because the expression of Dio2, Dio3, and TSHB showed significant differences in CBA/N mice at this time (Ono et al., 2008). Dio2 expression was constitutively upregulated in $M T 1^{-1-}$ and $M T 1^{-1-} M T 2^{-1-}$ mice regardless of the photoperiodic condition (one-way ANOVA, $p<0.0001$ ) (Fig. 2). However, Dio3 expression was constitutively downregulated in these genotypes (one-way ANOVA, $p<0.0001$ ) (Fig. 2). Photoperiodic changes in Dio3 expression were detected in wild-type $\mathrm{C} 3 \mathrm{H}$ and $M T 2^{-1-}$ ( $t$ test, $p<0.05$ for wild type; $p<0.01$ for $\left.M T 2^{-1-}\right)$, but the changes were abolished in $\mathrm{MT1}^{-1-}$ and $M T 1^{-I-}, M T 2^{-I-}$ mice (Fig. 2). The suppression of Dio3 expression under long-day condition was stronger in $M T 2^{-1-}$ mice than in wild-type mice ( $t$ test, $p<0.01$ ) (Fig. 2).

\section{Effects of melatonin injections on Dio2 and Dio3 in MT1- deficient C57BL mice}

As also shown by Ono et al. (2008), Dio2 was suppressed and Dio3 was upregulated in wild-type C57BL mice injected with melatonin at ZT14 under long-day condition ( $t$ test, $p<0.05$ ) (Fig. 3). These effects were abolished by targeted disruption of MT1 (Fig. 3).

\section{Discussion}

Previous work has shown that the mouse circadian system encodes seasonal light cycles at the neural network level (Inagaki et al., 2007; VanderLeest et al., 2007; Watanabe et al., 2007a) although mice are not strongly photoperiodic in their reproductive behavior or physiology. In accordance with a recent report by Ono et al. (2008), our study demonstrates that mice are indeed suitable models to study molecular mechanisms of photoperiodic regulation at the hypothalamo-hypophysial level. Thus, the expression of genes shown to control the photoperiodic gonadal response at the hypothalamo-hypophysial level in quail and sheep (e.g., TSHB in the PT, Dio2 and Dio3 in the EC) (Hanon et al., 2008; Nakao et al., 2008) is regulated by photoperiod in melatonin-proficient CBA/N mice and by melatonin in melatonin-deficient C57BL mice (Ono et al., 2008). In this study, we showed that Dio3 expression in melatonin-proficient wild-type $\mathrm{C} 3 \mathrm{H}$ mice was lower under long-day condition than under short-day condition. This was also found in CBA/N mice (Ono et al., 2008), Djungarian hamsters (Barrett et al., 2007; Watanabe et al., 2007b), and Japanese quail (Yasuo et al., 2005). Dio2 expression did not respond to photoperiodic changes in wild-type $\mathrm{C} 3 \mathrm{H}$, whereas it was strongly induced by long-day condition in CBA/N mice (Ono et al., 2008), Syrian hamsters (Revel et al., 2006; Yasuo et al., 2007), and Japanese quail (Yoshimura et al., 2003; Yasuo et al., 2005). In Djungarian hamsters, Dio2 expression was induced when animals were transferred from short to long days, but it did not change when animals were transferred from long to short days (Watanabe et al., 2004, 2007b; Barrett et al., 2007). Thus, the effects of photoperiod on gene expression in the EC appear to be specific for species, strain, and experimental schedule, and $\mathrm{C} 3 \mathrm{H}$ mice in our breeding colony can be used for research on photoperiodic regulation of Dio3 expression.

The studies on wild-type mice have opened the way to use genetically manipulated mice to further analyze the molecular mechanisms underlying photoperiodic regulation. Using mice with targeted disruption of melatonin receptor types (MT1, $\mathrm{MT} 2$, and both types) on $\mathrm{C} 3 \mathrm{H}$ genetic background, we were for the first time able to analyze distinct functions of each receptor type for the photoperiodic response of Dio3 expression in the EC. In $M T 1^{-1-}$ and $M T 1^{-1-} M T 2^{-1-}$ mice, photoperiodic changes in Dio3 expression were completely abolished, whereas $M T 2^{-1-}$ mice retained the response. Moreover, melatonin injections suppressed Dio2 and induced Dio3 expression in wild-type C57BL mice as has also been shown by Ono et al. (2008). These effects were abolished by targeted disruption of MT1. The data indicate that MT1 is crucial for the photoperiodic response of gene expression in the EC and, as a consequence, for the photoperiodic gonadal regulation. Further evidence for the involvement of MT1 in the control of Dio2 and Dio3 expression is provided by the observation that overall levels of Dio2 mRNA were upregulated and those of Dio3 mRNA were suppressed in $\mathrm{C} 3 \mathrm{H}$ mice with targeted disruption of MT1 and MT1/MT2. Notably, these changes were not seen in melatonin-deficient C57BL with targeted disruption of MT1. Together, the data suggest that melatonin affects the expression of Dio2 and Dio3 by acting on MT1.

With regard to the location of this receptor, it should be noted that the EC itself does not express melatonin receptors (Schuster et al., 2000; Song and Bartness, 2001). A synopsis of several previous studies and our present results indicates that the expression of Dio2 and Dio3 in the EC is regulated via MT1 located in the PT: (1) The PT is the target site for seasonal melatonin signaling 
(Reppert et al., 1994; Gauer et al., 1998; von Gall et al., 2002b); (2) it contains high levels of MT1 mRNA but lacks MT2 mRNA (Reppert et al., 1995); (3) MT1 mRNA and TSHB protein are colocalized in the PT of rat (Klosen et al., 2002), and immunosignals of TSHB in the PT of MT1-deficient $\mathrm{C} 3 \mathrm{H}$ mice are constitutively upregulated (C. von Gall, unpublished observation); (4) TSH produced in the PT was shown to regulate Dio2 and Dio3 expression in the EC in Japanese quail (Nakao et al., 2008), sheep (Hanon et al., 2008), and mice (Ono et al., 2008).

Notably, $M T 2^{-1-}$ mice showed a stronger photoperiodic responsiveness of Dio3 expression than wild-type mice. This effect was not seen in $M T 1^{-1-} M T 2^{-1-}$ mice, suggesting that MT2 may weaken the photoperiodic responses by interference with MT1 function. This speculation may explain the high responsiveness to photoperiod in hamsters which lack a functional MT2 receptor (Weaver et al., 1996) and imply the adaptation of hamsters to environment by natural mutation of MT2 protein that is disadvantageous for the photoperiodic gonadal regulation.

In summary, we could for the first time provide clear evidence for distinct functions of MT1 and MT2 in photoperiodic regulation at the hypothalamo-hypophysial level: MT1 is crucial for the photoperiodic response of genes in the mediobasal hypothalamus which regulate the photoperiodic gonadal responses. MT2 may weaken the responsiveness of these genes to photoperiod in the presence of MT1. These data provide new insight into the molecular mechanisms of photoperiodic gonadal regulation, and the interaction of MT1 and MT2 would be an interesting research topic in the future.

\section{References}

Barrett P, Ebling FJ, Schuhler S, Wilson D, Ross AW, Warner A, Jethwa P, Boelen A, Visser TJ, Ozanne DM, Archer ZA, Mercer JG, Morgan PJ (2007) Hypothalamic thyroid hormone catabolism acts as a gatekeeper for the seasonal control of body weight and reproduction. Endocrinology 148:3608-3617.

Bartness TJ, Powers JB, Hastings MH, Bittman EL, Goldman BD (1993) The timed infusion paradigm for melatonin delivery - what has it taught us about the melatonin signal, its reception, and the photoperiodic control of seasonal responses. J Pineal Res 15:161-190.

Boutin JA, Audinot V, Ferry G, Delagrange P (2005) Molecular tools to study melatonin pathways and actions. Trends Pharmacol Sci 26:412-419.

Dubocovich ML, Yun K, Al-Ghoul WM, Benloucif S, Masana MI (1998) Selective MT2 melatonin receptor antagonists block melatonin-mediated phase advances of circadian rhythms. FASEB J 12:1211-1220.

Gauer F, Schuster C, Poirel VJ, Pévet P, Masson-Pévet M (1998) Cloning experiments and developmental expression of both melatonin receptor $\mathrm{Mel}_{1 \mathrm{~A}}$ mRNA and melatonin binding sites in the Syrian hamster. Mol Brain Res 60:193-202.

Hanon EA, Lincoln GA, Fustin JM, Dardente H, Masson-Pévet M, Morgan PJ, Hazlerigg DG (2008) Ancestral TSH mechanism signals summer in a photoperiodic mammal. Curr Biol 18:1147-1152.

Inagaki N, Honma S, Ono D, Tanahashi Y, Honma K (2007) Separate oscillating cell groups in mouse suprachiasmatic nucleus couple photoperiodically to the onset and end of daily activity. Proc Natl Acad Sci U S A 104:7664-7669.

Jilg A, Moek J, Weaver DR, Korf HW, Stehle JH, von Gall C (2005) Rhythms in clock proteins in the mouse pars tuberalis depend on MT1 melatonin receptor signalling. Eur J Neurosci 22:2845-2854.

Jin X, von Gall C, Pieschl RL, Gribkoff VK, Stehle JH, Reppert SM, Weaver DR
(2003) Targeted disruption of the mouse $\mathrm{Mel}_{1 \mathrm{~b}}$ melatonin receptor. Mol Cell Biol 23:1054-1060.

Klosen P, Bienvenu C, Demarteau O, Dardente H, Guerrero H, Pévet P, Masson-Pévet M (2002) The mtl Melatonin receptor and ROR $\beta$ receptor are co-localized in specific TSH-immunoreactive cells in the pars tuberalis of the rat pituitary. J Histochem Cytochem 50:1647-1657.

Liu C, Weaver DR, Jin X, Shearman LP, Pieschl RL, Gribkoff VK, Reppert SM (1997) Molecular dissection of two distinct actions of melatonin on the suprachiasmatic circadian clock. Neuron 19:91-102.

Nakao N, Ono H, Yamamura T, Anraku T, Takagi T, Higashi K, Yasuo S, Katou Y, Kageyama S, Uno Y, Kasukawa T, Iigo M, Sharp PJ, Iwasawa A, Suzuki Y, Sugano S, Niimi T, Mizutani M, Namikawa T, Ebihara S, Ueda HR, Yoshimura T (2008) Thyrotrophin in the pars tuberalis triggers photoperiodic response. Nature 452:317-322.

Ono H, Hoshino Y, Yasuo S, Watanabe M, Nakane Y, Murai A, Ebihara S, Korf HW, Yoshimura T (2008) Involvement of thyrotropin in photoperiodic signal transduction in mice. Proc Natl Acad Sci USA 105:18238-18242.

Reppert SM, Weaver DR, Ebisawa T (1994) Cloning and characterization of a mammalian melatonin receptor that mediates reproductive and circadian responses. Neuron 13:1177-1185.

Reppert SM, Godson C, Mahle CD, Weaver DR, Slaugenhaupt SA, Gusella JF (1995) Molecular characterization of a second melatonin receptor expressed in human retina and brain: the $\mathrm{Mel}_{1 \mathrm{~b}}$ melatonin receptor. Proc Natl Acad Sci U S A 92:8734-8738.

Revel FG, Saboureau M, Pévet P, Mikkelsen JD, Simonneaux V (2006) Melatonin regulates type 2 deiodinase gene expression in the Syrian hamster. Endocrinology 147:4680-4687.

Schuster C, Gauer F, Guerrero H, Lakhdar-Ghazal N, Pevet P, Masson-Pevet M (2000) Photic regulation of mtl melatonin receptors in the Siberian hamster pars tuberalis and suprachiasmatic nuclei: involvement of the circadian clock and intergeniculate leaflet. J Neuroendocrinol 12:207-216.

Song CK, Bartness TJ (2001) CNS sympathetic outflow neurons to white fat that express MEL receptors may mediate seasonal adiposity. Am J Physiol Regul Integr Comp Physiol 281:R666-R672.

VanderLeest HT, Houben T, Michel S, Deboer T, Albus H, Vansteensel MJ, Block GD, Meijer JH (2007) Seasonal encoding by the circadian pacemaker of the SCN. Curr Biol 17:468-473.

von Gall C, Garabette ML, Kell CA, Frenzel S, Dehghani F, Schumm-Draeger PM, Weaver DR, Korf HW, Hastings MH, Stehle JH (2002a) Rhythmic gene expression in pituitary depends on heterologous sensitization by the neurohormone melatonin. Nat Neurosci 5:234-238.

von Gall C, Stehle JH, Weaver DR (2002b) Mammalian melatonin receptors: molecular biology and signal transduction. Cell Tissue Res 309:151-162.

von Gall C, Weaver DR, Moek J, Jilg A, Stehle JH, Korf HW (2005) Melatonin plays a crucial role in the regulation of rhythmic clock gene expression in the mouse pars tuberalis. Ann N Y Acad Sci 1040:508-511.

Watanabe M, Yasuo S, Watanabe T, Yamamura T, Nakao N, Ebihara S, Yoshimura T (2004) Photoperiodic regulation of type 2 deiodinase gene in 
Djungarian hamster: possible homologies between avian and mammalian photoperiodic regulation of reproduction. Endocrinology 145:1546-1549.

Watanabe T, Naito E, Nakao N, Tei H, Yoshimura T, Ebihara S (2007a) Biomodal clock gene expression in mouse suprachiasmatic nucleus and peripheral tissues under a 7-hour light and 5-hour dark schedule. J Biol Rhythms 22:58-68.

Watanabe T, Yamamura T, Watanabe M, Yasuo S, Nakao N, Dawson A, Ebihara S, Yoshimura T (2007b) Hypothalamic expression of thyroid hormone-activating and -inactivating enzyme genes in relation to photorefractoriness in birds and mammals. Am J Physiol 292:R568-R572.

Weaver DR, Liu C, Reppert SM (1996) Nature's knockout: the Mel $_{1 \mathrm{~b}}$ receptor is not necessary for reproductive and circadian responses to melatonin in Siberian hamsters. Mol Endocrinol 10:1478-1487.
Yasuo S, Watanabe M, Nakao N, Takagi T, Follett BK, Ebihara S, Yoshimura $\mathrm{T}$ (2005) The reciprocal switching of two thyroid hormone-activating and-inactivating enzyme genes is involved in the photoperiodic gonadal response of Japanese quail. Endocrinology 146:2551-2554.

Yasuo S, Yoshimura T, Ebihara S, Korf HW (2007) Temporal dynamics of type 2 deiodinase expression after melatonin injections in Syrian hamsters. Endocrinology 148:4385-4392.

Yoshimura T, Suzuki Y, Makino E, Suzuki T, Kuroiwa A, Matsuda Y, Namikawa T, Ebihara S (2000) Molecular analysis of avian circadian clock genes. Brain Res Mol Brain Res 78:207-215.

Yoshimura T, Yasuo S, Watanabe M, Iigo M, Yamamura T, Hirunagi K, Ebihara S (2003) Light-induced hormone conversion of $\mathrm{T}_{4}$ to $\mathrm{T}_{3}$ regulates photoperiodic response of gonads in birds. Nature 426:178-181. 